\title{
Formulation of Binucleate Rhizoctonia spp. and Biocontrol of Rhizoctonia solani on Impatiens
}

\author{
E. W. Honeycutt and D. M. Benson, Department of Plant Pathology, North Carolina State University, Raleigh \\ 27695
}

\begin{abstract}
Honeycutt, E. W., and Benson, D. M. 2001. Formulation of binucleate Rhizoctonia spp. and biocontrol of Rhizoctonia solani on impatiens. Plant Dis. 85:1241-1248.

Isolates BNR621 and P9023 of binucleate Rhizoctonia spp. (BNR) in Pesta and rice flour formulations were evaluated for control of preemergence damping-off of impatiens caused by $R$. solani. Amendment of a soilless potting mix with the formulations at $0.47 \%$ (vol:vol) 3 days prior to seeding and infesting did not improve control compared to amendment 1 day prior to seeding and infesting regardless of whether the moistened amended potting mix was stored in closed plastic bags or in plug trays under a mist system. BNR fungi were no more effective in biocontrol of $R$. solani in formulations amended at $0.9 \%$. Control of damping-off was comparable but not consistent between formulations of BNR fungi and the fungicide thiophanatemethyl. Damping-off was controlled better with formulations of BNR fungi than with SoilGard based on Trichoderma virens. Shelf life of Pesta and rice flour formulations at $4^{\circ} \mathrm{C}$ was determined by assessing viability of BNR isolates over time. Viability of the BNR isolates, measured as CFU/g of formulation, declined to approximately 68 to $79 \%$ of the original propagule concentration after 6 months in Pesta and rice flour formulations, with the greatest decline in the first 2 months. Shelf life of BNR isolates in formulation significantly affected control of preemergence damping-off but was isolate dependent. Preemergence damping-off was only 5 to $7 \%$ with fresh formulations but increased to 30 to $50 \%$ with 4 -month-old formulations. Controlled atmospheres, maintained with saturated salt solutions, were established to measure the effect of water activity on shelf life of formulations. Water activities $\left(a_{w}\right)$ of 0.12 and $0.33 a_{w}$ enhanced BNR survival in formulations by approximately 2 to 3 months compared with $\mathrm{a}_{\mathrm{w}}$ of 0.53 and $0.75 \mathrm{a}_{\mathrm{w}}$. Storage of Pesta and rice flour formulations at $4{ }^{\circ} \mathrm{C}$ significantly improved BNR survival by 4 to 5 months compared with storage at $25^{\circ} \mathrm{C}$. These results suggest that improved shelf life of BNR isolates is needed before formulated products can be developed for biocontrol of preemergence damping-off.
\end{abstract}

Formulation of biocontrol agents is a key step in the development of commercial biocontrol products once effective strains have been identified and characterized. A formulated product must be economical to produce, easy to apply in the crop production system, efficacious with an adequate number of viable cells when used, and able to maintain the viability or shelf life of the agent for a sufficient period to be marketed

Corresponding author: D. M. Benson

E-mail: mike_benson@ncsu.edu

This research was supported in part by the North Carolina Agricultural Research Service, North Carolina State University, Raleigh, and by a grant from the USDA CSREES Southern Region IPM Program.

This publication reports research involving an antimicrobial substance. It does not contain recommendations for its use, nor does it imply that the uses discussed here have been registered. All uses of pesticides must be registered by appropriate state and federal agencies before they can be recommended.

Accepted for publication 10 August 2001.

Publication no. D-2001-0928-01R

(c) 2001 The American Phytopathological Society
(26). A number of formulations for fungal biocontrol agents have been developed, including alginate prill for Talaromyces flavus (13) and Gliocladium virens G1-21, the first fungal biocontrol agent registered by the United States Environmental Protection Agency for soilborne plant pathogens (27); pregelatinized starch-flour formulations of $G$. virens and Trichoderma hamatum (23); Pesta, a semolina-clay based formulation for mycoherbicides such as Alternaria spp., Colletotrichum spp., and Fusarium spp. (8); and rice flour, a unique formulation for mycoherbicidal strains of Fusarium oxysporum (17).

Preemergence damping-off caused by Rhizoctonia solani Kühn can be a major disease problem of bedding plants produced in commercial greenhouses (7). Although practices including sanitation, pathogen-free potting mix, and fungicides are used to manage this disease, the pathogen can persist in commercial greenhouses. With crops like bedding plants, which accounted for $\$ 1.9$ billion in sales in the United States in 1999 (1), growers may be reluctant to use fungicides where inhibition of seed germination and rooting is a concern (D. M. Benson, unpublished data). Biocontrol provides an ecologically based approach to integrated pest management (IPM) and an alternative to fungicide use that has the potential to promote sustainable agriculture in crop production systems.

Several genera of fungi, including Trichoderma (11,15), Gliocladium $(20,25)$, Cladorrhinum (24), and binucleate Rhizoctonia $(4,29)$, have been evaluated for control of $R$. solani. Binucleate Rhizoctonia spp. (BNR) controlled Rhizoctonia diseases on bean (4), bedding plants (16), cabbage (29) cucumber (30), and potato (12). BNR also have been shown to control Pythium diseases $(3,10)$.

The overall objective of this study was to evaluate the efficacy of two isolates of BNR in two formulations for control of preemergence damping-off of impatiens caused by $R$. solani. Our specific objectives were to (i) determine the effect of rate of formulation and method of incubating potting mix amended with formulated BNR on subsequent control of $R$. solani, (ii) investigate the viability and biocontrol efficacy of BNR isolates in Pesta and rice flour formulations after various storage times, and (iii) investigate the effect of storage conditions (i.e., water activity and temperature) on survival of BNR. in Pesta and rice flour formulations. Preliminary results have been reported $(18,19)$.

\section{MATERIALS AND METHODS}

Isolates of Binucleate Rhizoctonia spp. Two isolates of BNR, BNR621 (formerly CG-232, obtained from pine bark used in potting mix) and $\mathrm{P} 9023$ (obtained from the roots of plantain in North Carolina), were tested as biocontrol agents based on previous results $(6,12)$. Both isolates were from the collection of Eddie Echandi maintained at North Carolina State University. Cultures of BNR isolates were grown on potato dextrose agar (PDA; Difco Laboratories, Detroit) on the lab bench and stored in screw-capped test tubes as 3-mm-diameter mycelial disks in sterile water at $20^{\circ} \mathrm{C}$. To prepare biomass of BNR isolates for formulation, a mycelial disk was transferred to a PDA plate. Four agar disks $(3 \mathrm{~mm}$ in diameter) from the margin of an actively growing culture of a BNR isolate then were transferred aseptically into 1-liter flasks of wheat bran $(50 \mathrm{~g}$ of wheat bran and $50 \mathrm{ml}$ of deionized water) that had been autoclaved on two successive days to kill spore-forming bacteria. Wheat bran cultures were incubated at room tem- 
perature for 9 days to produce biomass of BNR fungi (3). Only hyphal fragments of BNR fungi were found in examination of wheat bran biomass.

Formulation of biocontrol agents. Two formulations of the BNR fungi were compared: Pesta (8) and rice flour (17). Except where noted, all ingredients were purchased at a local health food store. Pesta formulation was prepared by combining $160 \mathrm{~g}$ of semolina flour and $40 \mathrm{~g}$ of kaolin (Feldspar Corp., Edgar, FL) in a mixing bowl (8). The contents of one flask of colonized wheat bran (biomass) were stirred into the semolina-kaolin mixture and $110 \mathrm{ml}$ of deionized water was added to form workable dough. Rice flour formulation was prepared by combining $75 \mathrm{~g}$ of rice flour, $25 \mathrm{~g}$ of kaolin, $10 \mathrm{~g}$ of vermiculite (Palmetto Vermiculite Co., Woodruff, $\mathrm{SC}$ ), and $14 \mathrm{~g}$ of gluten in a mixing bowl (17). Then, $70 \mathrm{~g}$ of biomass and $14 \mathrm{ml}$ of canola oil were combined with the other ingredients. Deionized water $(80 \mathrm{ml})$ was added to form workable dough. Pesta (P) and rice flour $(\mathrm{RF})$ doughs were rolled into thin $(1$ to $2 \mathrm{~mm}$ ) sheets and placed on fiberglass screens to dry overnight in a laminar flow hood. Dried formulations were then pulverized in a Waring blender to produce granules, passed through a $2-\mathrm{mm}$ sieve, and stored in closed plastic bags at $4^{\circ} \mathrm{C}$ prior to use.

Inoculum. Isolate RS3 of $R$. solani AG4 (deposited in the United States Department of Agriculture-Agricultural Research Service culture collection at Peoria, IL as NRRL 22805) from poinsettia (Euphorbia pulcherrima) with stem rot was maintained on PDA slants at $20^{\circ} \mathrm{C}$ in the dark. RS3 is highly virulent to impatiens, causing both preemergence damping-off and crown rot (D. M. Benson, unpublished data). Inoculum was prepared by placing three 3-mm agar disks from the margins of actively growing cultures of $R$. solani into $125-\mathrm{ml}$ flasks of rice grains ( $25 \mathrm{~g}$ of rice and 18 $\mathrm{ml}$ water) that had been autoclaved for 40 min at $121^{\circ} \mathrm{C}$ on two consecutive days. Cultures were incubated for 7 days at about $25^{\circ} \mathrm{C}$ on the lab bench. Flasks were shaken briefly each day to assure uniform colonization of rice grains by $R$. solani. Colonized rice grains were pulverized in a Waring blender and passed through a 2$\mathrm{mm}$ sieve to produce moist granules of inoculum with a uniform range of particle sizes. A $120-\mathrm{cm}^{3}$ aliquot of potting mix reserved from each treatment described below and $0.1 \mathrm{~g}$ of rice granules colonized by $R$. solani was mixed thoroughly by mechanically rotating the mixture in a $500-\mathrm{cm}^{3}$ plastic bottle for $2 \mathrm{~min}$ prior to covering the seeded tray. Preliminary experiments with isolate RS3 had shown that $0.1 \mathrm{~g}$ of rice granule inoculum of $R$. solani caused 60 to $80 \%$ preemergence damping-off in impatiens, a range of disease judged optimum for biocontrol experiments.
Biocontrol experiments. Three sets of experiments were conducted in the greenhouse. In the first, the method (closed bags versus misted trays) and time ( 1 or 3 days) of incubating potting mix amended with formulation prior to seeding and covering with infested mix was compared. Fafard Mix \#2, a soilless mix containing sphagnum peat moss, horticultural vermiculite, and horticultural perlite plus wetting agent and starter nutrients (Fafard Inc., Agawam, MA) with a $\mathrm{pH}$ of 5.5 to 6.5 , was moistened with tap water in a cement mixer to $65 \%$ moisture content by weight. The mix was added to black plastic bags at a rate of $7,000 \mathrm{~cm}^{3}$ per bag and then amended with $33 \mathrm{~cm}^{3}(0.47 \%$ vol:vol) of Pesta or rice flour formulation containing either isolate BNR621 or P9023. Bags were partially inflated and rotated for approximately 2 min to thoroughly incorporate formulation granules into the potting mix. The closed bags were placed on a greenhouse bench (daily temperature range of about 18 to $30^{\circ} \mathrm{C}$ ) out of direct sunlight for 1 or 3 days to promote colonization of the mix by BNR fungi prior to seeding and infesting with $R$. solani. One day prior to seeding, 81-cell plug trays were filled with the mix from the 3-day pretreatment and placed on a greenhouse bench under a mist system that misted for 2 min five times per day. Amended mix stored in bags for 1 day prior to seeding was not placed into plug trays until the day of seeding. In the other method, the potting mix amended with formulation was added directly to plug trays. Trays were placed under the mist system for 1 or 3 days prior to seeding. Each 81-cell tray had a surface area of $0.064 \mathrm{~m}^{2}$ that held $1,300 \mathrm{~cm}^{3}$ of potting mix and each tapered plug cell was 2.5 by 2.5 by $2.5 \mathrm{~cm}$ in size. In addition to the biocontrol treatments, a standard fungicide (thiophanate-methyl, Cleary 3336 50W; Cleary Chemical Co., Dayton, NJ) treatment was applied at rate of $0.6 \mathrm{~g} / \mathrm{liter}$ in a volume of $325 \mathrm{ml} /$ tray after seeds were covered as described below. There were two trials of the experiment with four replications per treatment.

In the second set of greenhouse experiments, the rate of formulation and efficacy in control of preemergence damping-off was compared. Formulations were amended to potting mix at either 0.47 or $0.9 \%$ (vol:vol) in plastic bags as described above. The amended potting mix was stored in the closed bags on the greenhouse bench for 3 days prior to seeding and infesting. Control treatments included the standard fungicide and Pesta and rice flour formulation with wheat bran but without BNR fungi. As a comparison, SoilGard (Olympic Horticultural Products, Co., Mainland, PA), a commercially available formulation of isolate GL-21 of Trichoderma virens, was amended to the potting mix at the label rate of $50.4 \mathrm{~cm}^{3}$ per 7,000 $\mathrm{cm}^{3}$ of $\operatorname{mix}\left(547 \mathrm{~g} / \mathrm{m}^{3}\right.$ or $0.72 \%$ vol:vol $)$ and stored in closed plastic bags for 3 days before seeding and infesting as above. There were three trials of the experiment with four replications of each treatment. Data were combined over trials for analysis of variance (ANOVA).

In the third set of greenhouse experiments, efficacy of BNR fungi in the Pesta formulation after various times in storage at $4^{\circ} \mathrm{C}$ was compared for control of preemergence damping-off of impatiens. A portion of fresh formulation ( 0 months) was compared to portions of the same batch of Pesta formulation after 4 and 6 months in storage. Pesta formulation at a rate of $0.47 \%$ in Fafard Mix \#2 was used. Amended potting mix was stored 3 days in closed plastic bags as described above. There were two trials of the experiment with four replications per treatment. Data was combined over trials for ANOVA.

For all greenhouse experiments, plug trays were seeded with impatiens (Impatiens wallerana cv. Super Elfin Mix, 90\% germination rate; Ball Horticultural Co., West Chicago, IL) by use of an 81-seed vacuum seeder that dropped seed onto the medium surface in each cell. Seeds in the plug tray then were covered uniformly with the infested potting mix described above by sprinkling the mixture through the lid of the $500-\mathrm{cm}^{3}$ plastic bottle (seven 8 -mm-diameter holes). Trays were maintained under the mist system, which provided enough water to keep the potting mix moist but never saturated. Stand counts in each tray were taken at 9, 12, and 15 days after seeding. Final stand counts were used to calculate percentage of preemergence damping-off based on seedling emergence in the noninfested control. Seedling emergence in the noninfested control treatments averaged $86 \%$ over experiments.

Greenhouse experiments with plug trays were arranged in a completely randomized block design. Data from individual trials of an experiment were combined when possible based on homogeneity of variances and lack of significant trial-treatment effects. Data were analyzed by ANOVA with the PROC GLM procedure of PC-SAS (SAS Institute, Inc., Cary, NC). Treatment means were separated by the least significant difference procedure. In the first two experiments that compared bag versus tray methods of incubating amended potting mix and effect of rate of formulation on disease control, the treatments included a factorial subset plus either three or four control treatments; therefore, factor main effects and interactions were tested using contrasts. Also, main effect means for isolate, method, and rate of formulation were each compared to the fungicide or SoilGard using contrasts. In the third greenhouse experiment, a two-way ANOVA was used so that the main effect of isolate and time could be compared. Stand counts for the noninfested control replications on which preemergence damping-off was 
based were not used in the analysis. Least square means for isolates were compared for each month, separately. Also, to examine effects of time, means for each month were compared separately for each isolate.

Shelf life of BNR isolates in formulations. Three 0.1-g subsamples of the Pesta and rice flour formulations of both BNR621 and P9023 were assayed once a month to determine viability of the biocontrol agents over time when stored at $4^{\circ} \mathrm{C}$. Each subsample was distributed over 10 plates of alkaline water agar with antibiotics at $\mathrm{pH} 8.5$ (14) and incubated for 1 to 2 days at about $25^{\circ} \mathrm{C}$ on the lab bench. Granules of formulation were observed under a dissecting microscope for emerging hyphae. A granule with emerging hyphae was counted as a CFU. Viability follows a curvilinear function over time (2); therefore, the number of CFU/g of formulation for each isolate at various times after formulation were logistically transformed: $y=\ln$ (proportion of CFU/g at time $[t] /[1$ - proportion of CFU/g at $t]$ ). The transformed data was analyzed by regression analysis with the PROC GLM procedure of PCSAS to compare the slope from the empirical logistic regression of isolate viability against time and the $\mathrm{SL}_{50}$ value (time to reach $50 \%$ viability of original formulation; 2). Data were combined from two trials of the experiment with three replications for analysis.

Water activity and shelf life of formulations. Water activity $\left(\mathrm{a}_{\mathrm{w}}\right)$ of a Pesta formulation of Colletotrichum truncatum was correlated with shelf life of this weed biocontrol agent (9); therefore, the effect of $a_{w}$ (the ratio of water vapor pressure over a sample to vapor pressure over pure water) of the formulations on viability of the BNR isolates over time was investigated. Multiplication of $\mathrm{a}_{\mathrm{w}}$ by 100 gives the relative humidity of the atmosphere over the sample. Approximately $7 \mathrm{~g}$ of Pesta or rice flour formulation (particle size greater than $600 \mu \mathrm{m}$ ) of a BNR isolate was placed in a 20-ml beaker, and the beaker was placed on an aluminum window screen supported above $200 \mathrm{ml}$ of a saturated salt solution in a $705-\mathrm{ml}$ white plastic jar. The 20-ml beaker and aluminum screen were supported above the salt solution by a crystallizing dish. Jars were kept at about $25^{\circ} \mathrm{C}$ on the lab bench. Over 14 to 17 days, the formulations equilibrated to the respective constant $\mathrm{a}_{\mathrm{w}}$ of $0.12,0.33,0.53$, and 0.75 that were established in each jar by use of saturated salt solutions of lithium chloride, magnesium chloride, magnesium nitrate, and sodium chloride, respectively, to control the atmosphere above the sample (9). A factorial design was used in all $a_{w}$ experiments.

The $\mathrm{a}_{\mathrm{w}}$ of an approximately 1-g subsample for each treatment was measured at $25^{\circ} \mathrm{C}$ with a CX-1 water activity system (Decagon Devices, Inc., Pullman, WA). An $\mathrm{a}_{\mathrm{w}}$ above the salt solutions measured with the CX-1 matched those values reported in the literature (31). Subsamples of formulation at each $\mathrm{a}_{\mathrm{w}}$ were assayed once a month as described above to determine BNR $\mathrm{CFU} / \mathrm{g}$ formulation. Samples of formulation held at the various constant $\mathrm{a}_{\mathrm{w}}$ were compared with samples held in uncontrolled environments at $4^{\circ} \mathrm{C}$ at about 0.56 $\mathrm{a}_{\mathrm{w}}$ or at $25^{\circ} \mathrm{C}$ at about $0.36 \mathrm{a}_{\mathrm{w}}$ in the absence of a saturated salt solution. CFU/g of formulation at each assay date was transformed by a logistic transformation, then analyzed by regression analysis as previously described to determine the slope of isolate viability against time and the $\mathrm{SL}_{50}$ value. Data for isolate and formulation were combined because no significant interactions occurred. The experiment was repeated with similar results.

\section{RESULTS}

Biocontrol of damping-off. In two trials, preemergence damping-off of impatiens caused by $R$. solani was less when either BNR621 or P9023 in the Pesta formulation was amended to the potting mix compared with the infested control (Fig. 1). Preemergence damping-off was 60 and $66 \%$ in the infested control in trials 1 and 2 of the experiment, respectively, but data could not be combined because overall disease was greater in trial 1 than in trial 2. In trial 1 , preemergence damping-off ranged from 19 to $41 \%$ and 22 to $35 \%$ for isolates BNR621 and P9023, respectively, (Fig. 1A). In trial 2, disease incidence ranged from 13 to $22 \%$ and 14 to $21 \%$ for BNR621 and P9023, respectively, (Fig. 1B). In both trials, no difference was found

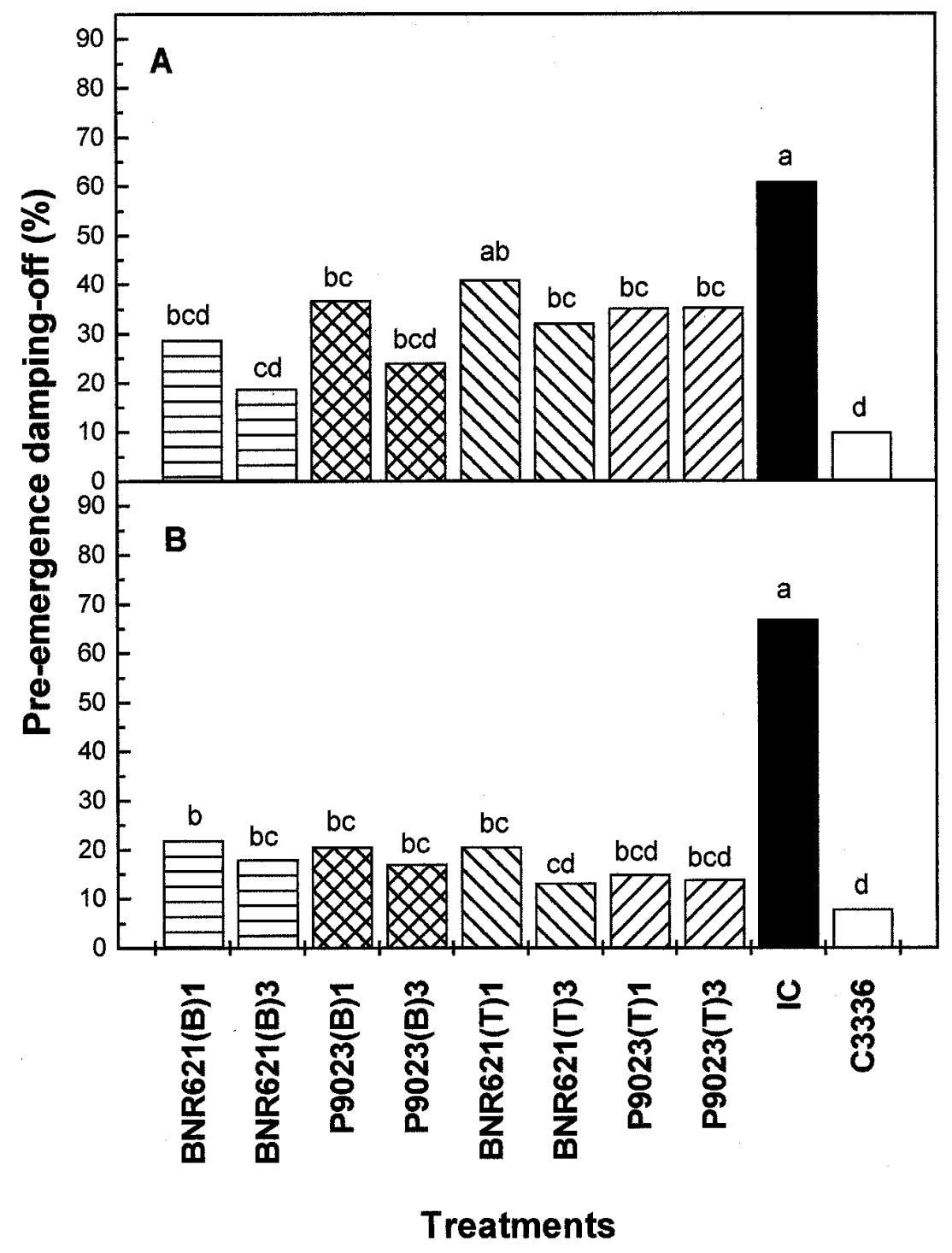

Fig. 1. Effect of closed plastic bag (B) or misted plug tray (T) method of storing potting mix amended with isolate BNR621 or P9023 of binucleate Rhizoctonia spp. (BNR) in a Pesta formulation on control of preemergence damping-off on impatiens seed caused by Rhizoctonia solani. Soilless mix amended with BNR was stored in either bags or misted in plug trays for 1 or 3 days prior to seeding and infesting the mix. Treatments with BNR were compared to the infested control (IC), and the fungicide thiophanate-methyl (C3336). Treatments within a trial with a different letter are significantly different $(P \leq 0.05)$ according to the least significant difference procedure. Factor main effects were separated by contrasts. A, Trial 1, B, trial 2 of the experiment. 
between efficacy of BNR isolate to control preemergence damping-off $(P=0.64$ and 0.43 for trials 1 and 2 , respectively). In both trials of the experiment, preemergence damping-off of impatiens was less than $10 \%$ when the fungicide thiophanatemethyl was applied. No biocontrol treatments were as effective as the fungicide in control of preemergence damping-off in trial $1(P=0.008)$, and only a 3 -day incubation of the potting mix with BNR621 and a 1- or 3-day incubation with P9023 in the Pesta formulation in plug trays was as effective as the fungicide in trial 2 (Fig. 1B). Amendment of soilless potting mix with the Pesta formulation of BNR isolates 3 days prior compared to amendment 1 day prior to seeding and infesting the covering mix with $R$. solani did not improve control of preemergence damping-off ( $P=0.15$ and 0.07 , trials 1 and 2, respectively; Fig. 1). No difference in control of preemergence damping-off was found between the plastic bag method and the misted plug tray method of incubating the Pesta formulation of BNR fungi in amended potting mix prior to seeding and infesting $(P=$ 0.11 and 0.09 , trials 1 and 2 , respectively; Fig. 1). However, neither method of incubating the BNR fungi prior to seeding and infesting controlled preemergence damping-off as well as the fungicide.

When the amendment rate for isolate BNR621 was increased from 0.47 to $0.9 \%$, preemergence damping-off of impatiens ranged from 11 to $20 \%$ and from 17 to $27 \%$, respectively, depending on formulation (Fig. 2). Preemergence damping-off of impatiens was slightly lower in treatments with formulations of P9023 compared with treatments with the BNR621 isolate. Disease incidence ranged from 8 to $10 \%$ for impatiens grown in the potting mix at the $0.47 \%$ amendment rate and 15 to $20 \%$ for impatiens in the mix at the $0.9 \%$ amendment rate among treatments with formulations of P9023 (Fig. 2). Preemergence damping-off was $68 \%$ in the infested control. When the effect of isolate was compared for control of preemergence damping-off, no difference between isolates was found $(P=0.12)$. There was no improvement in disease control with the higher rate of formulation amendment $(P=0.06)$. Finally, no difference in disease control was found between the two formulations of BNR isolates tested $(P=0.60)$.

Preemergence damping-off of impatiens in treatments receiving formulations containing no biocontrol agent was similar or higher than in the infested control (Fig. 2).

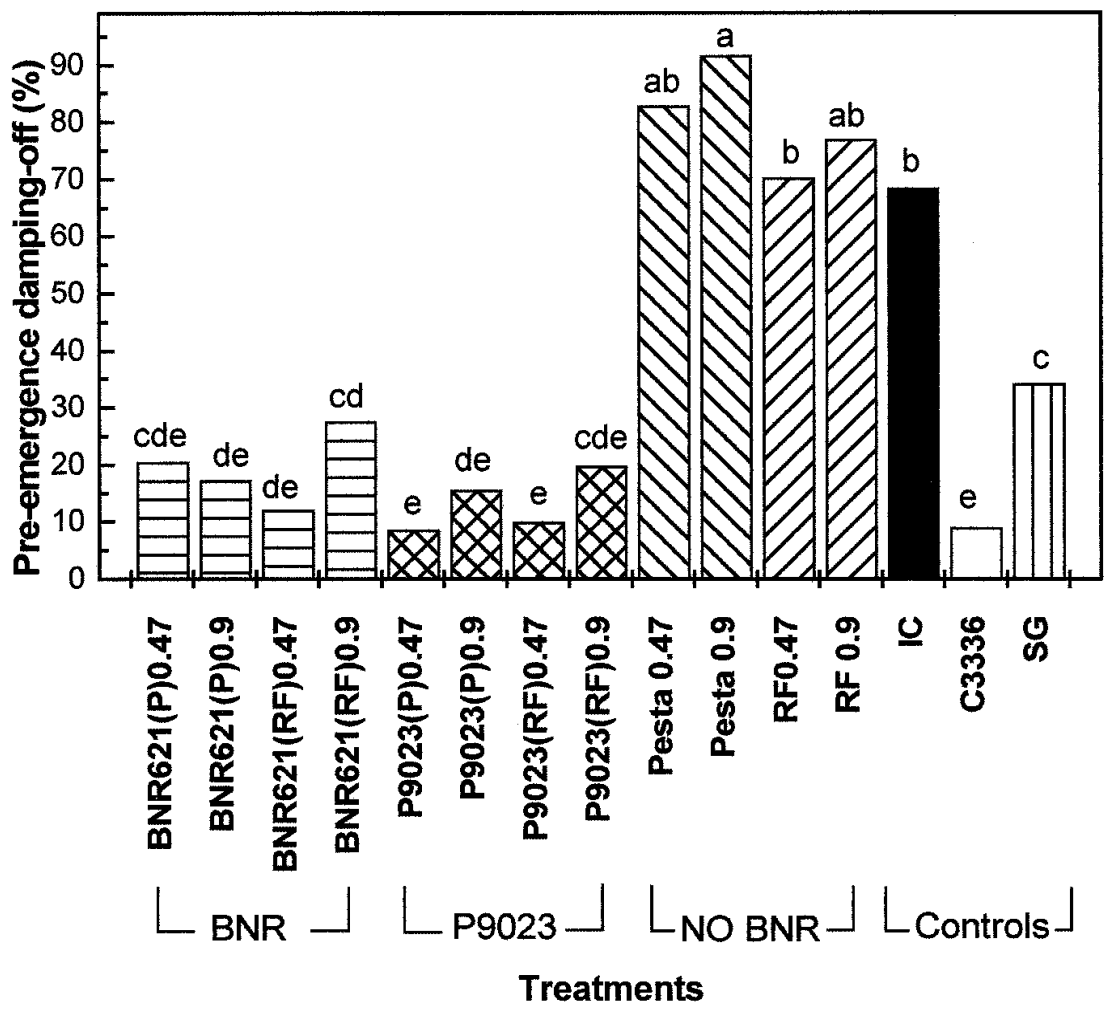

Fig. 2. Effect of 0.47 and $0.9 \%$ rates of amendment of Pesta (P) and rice flour (RF) formulations containing isolate BNR621 (BNR) or P9023 (P9023) of binucleate Rhizoctonia spp. on control of preemergence damping-off of impatiens seed caused by Rhizoctonia solani. Identical rates of Pesta and rice flour formulations without binucleate Rhizoctonia spp. (No BNR) also were used. SoilGard (SG), the fungicide thiophanate-methyl (C3336), and an infested control (IC) were used for comparison (Controls). Each bar is the mean of four replications averaged over three trials of the experiment. Treatments with a different letter are significantly different $(P \leq 0.05)$ according to the least significant difference procedure. Factor main effects were separated by contrasts.
Preemergence damping-off of impatiens was 9 and $32 \%$ in mix treated with thiophanate-methyl or amended with SoilGard, respectively (Fig. 2). Disease incidence of impatiens in treatments with BNR fungi combined over rate and formulation was not different $(P=0.18)$ than disease incidence with thiophanate-methyl, but significantly less $(P=0.004)$ than preemergence damping-off in the SoilGard treatment.

Shelf life of BNR in formulations. Viability of BNR isolates, based on CFU/g of formulation, was determined each month to determine the length of survival in Pesta and rice flour formulations stored at $4{ }^{\circ} \mathrm{C}$. After 2 months, CFU/g of formulation for isolates BNR621 in Pesta, P9023 in Pesta, BNR621 in rice flour, and P9023 in rice flour declined by 44, 57, 46, and 57\%, respectively (Fig. 3). Between 2 and 6 months, a more gradual decline in viability occurred. At 6 months, CFU for BNR621 in Pesta, P9023 in Pesta, BNR621 in rice flour, and P9023 in rice flour were similar at $25,23,29$, and $31 \%$, respectively, of the original populations. After a logistic transformation of survival data from two trials of the experiment (Fig. 3), no differences in the rate of change of isolate viability over time (slope; $P=0.56$ ) or the $\mathrm{SL}_{50}$ value $(P=0.31)$ were observed between BNR isolates or formulations. In the Pesta formulation, the slope for isolate BNR621 was -0.61 with an $\mathrm{SL}_{50}$ of 4.1 months, compared with a slope of -0.55 and $\mathrm{SL}_{50}$ of 2.8 months for isolate P9023. In the rice flour formulation, the slope for isolate BNR621 was -0.44 with an $\mathrm{SL}_{50}$ of 3.6 months, compared with a slope of -0.52 and $\mathrm{SL}_{50}$ of 3.8 months for isolate P9023.

Shelf life and efficacy of formulation. The decline in viability of BNR621 and P9023 in formulation over time reduced disease control efficacy. Damping-off of impatiens in treatments with fresh Pesta formulations of BNR621 and P9023 (0 months) was 8 and $5 \%$, respectively, and less $(P=0.003)$ than the $71 \%$ in the infested control (Fig. 4). However, in experiments that used 4-month-old formulations, damping-off was 50 and $30 \%$ for isolates BNR621 and P9023, respectively, compared with $85 \%$ in the infested control (Fig. 4). At 4 months, control of preemergence damping-off was less for isolate BNR621 $(P=0.01)$ but not isolate P9023 $(P=0.059)$ compared with control of damping-off with these isolates in the fresh formulation. At 4 months, viability of BNR fungi in the Pesta formulation had declined from a range of 1,650 to $2,200 \mathrm{CFU} / \mathrm{g}$ at formulation to a range of 750 to 1,050 CFU/g (Fig. 3). Disease incidence in impatiens was 40 and $20 \%$ in experiments with 6-month-old formulations of BNR621 and P9023, respectively, compared with $76 \%$ in the infested control (Fig. 4). At 6 months, control of damping-off was less with isolate BNR621 $(P=0.027)$ but not P9023 ( $P$ $=0.282)$ compared with control with fresh 
formulations of these isolates. Viability was even lower at 6 months, ranging from about 450 to $700 \mathrm{CFU} / \mathrm{g}$. When 4- and 6month-old formulations of each isolate were compared for disease control, no difference was found for either BNR621 ( $P$ $=0.398)$ or P9023 $(P=0.263)$.

$\mathbf{a}_{\mathrm{w}}$ of formulations and shelf life. The number of CFU/g of formulation declined at different rates depending on the $a_{w}$ of the Pesta and rice flour formulations. Shelf life of formulations was shortest (2 months) at $0.75 \mathrm{a}_{\mathrm{w}}$ and greatest (6 months) at $0.12 \mathrm{a}_{\mathrm{w}}$, regardless of isolate or formulation tested (Fig. 5). In the uncontrolled atmosphere at $4^{\circ} \mathrm{C}$, viability of BNR isolates in both the Pesta and rice flour formulations declined more slowly even though $a_{w}$ was relatively high (about $0.56 \mathrm{a}_{\mathrm{w}}$ ), but never reached 0 $\mathrm{CFU} / \mathrm{g}$ over the 6-month period. In the uncontrolled atmosphere at $25^{\circ} \mathrm{C}$, both BNR fungi reached $0 \mathrm{CFU} / \mathrm{g}$ after 4 months (Fig. 5). Viability data for BNR fungi at each $\mathrm{a}_{\mathrm{w}}$ were combined, because there were no interactions between isolate and formulation. Slope values of CFU over time declined at the greatest rate when moisture levels were higher (i.e., at 0.53 and $0.75 \mathrm{a}_{\mathrm{w}}$; Table 1). A significantly slower decline $(P \leq 0.05)$ in viability was found at lower moisture levels (i.e., at 0.12 and $0.33 \mathrm{a}_{\mathrm{w}}$; Table 1). $\mathrm{SL}_{50}$ values were less than 1 month at 0.53 and $0.75 \mathrm{a}_{\mathrm{w}}$; however, at 0.12 and $0.33 \mathrm{a}_{\mathrm{w}}, \mathrm{SL}_{50}$ values were 2.2 and 1.8 months, respectively. In the uncontrolled atmospheres, the $\mathrm{SL}_{50}$ value was over 4 months at $4^{\circ} \mathrm{C}$ but only 1.4 months at $25^{\circ} \mathrm{C}$ (Table 1 ).

\section{DISCUSSION}

Pesta and rice flour formulations of both isolates of BNR fungi provided effective control of preemergence damping-off of impatiens caused by $R$. solani. Disease control with the two formulations of either BNR isolate was similar to the standard fungicide treatment of thiophanate-methyl and better than that with the commercial biocontrol product SoilGard. Biocontrol of Rhizoctonia diseases by BNR fungi have been reported on bean $(4,5)$, cabbage (29), potato (12), and cucumber (30). Harris et. al. (16) reported that isolates of BNR were effective for control of damping-off caused by $R$. solani in bedding plants such as Capsicum spp. In this study, we investigated the effect that different types of formulation, time of amendment period to seeding, rate of amendment with formulated BNR fungi, and storage conditions of formulation all have on the control of preemergence damping-off on impatiens by BNR fungi.

Amending soilless potting mix with formulated BNR fungi for 3 days or 1 day in closed plastic bags or misted plug trays prior to seeding and infesting had no effect on the level of suppression of preemergence damping-off of impatiens. Burns and Benson (3) reported similar results for biocontrol of Pythium ultimum on vinca (Catharanthus roseus) with BNR isolates; however, they found that increasing the interval to 6 days between amending and seeding and infesting improved disease control. Presumably, the longer period between amendment of the mix and seeding and infesting allowed the BNR fungi a

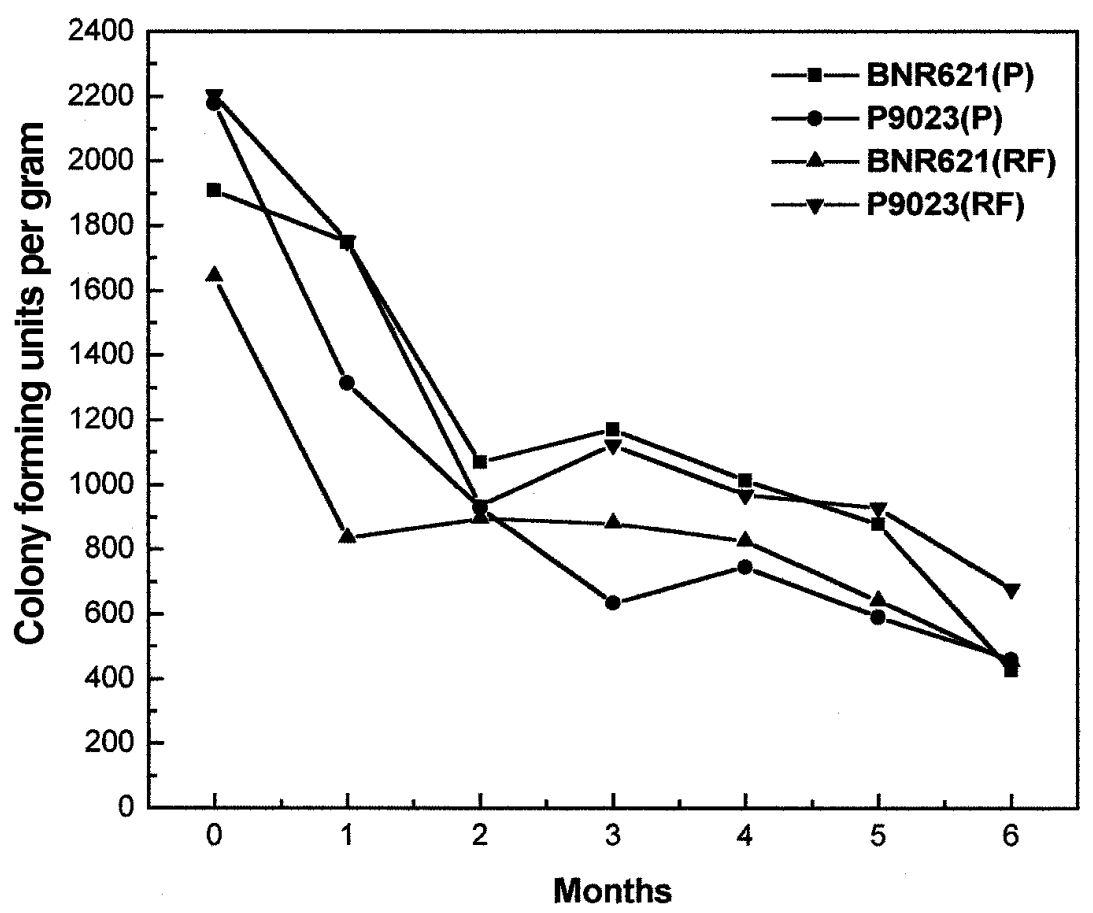

Fig. 3. Shelf life (viability) of Pesta (P) and rice flour (RF) formulations containing isolate BNR621 or $\mathrm{P} 9023$ of binucleate Rhizoctonia spp. stored in closed plastic bags over a 6-month period at $4^{\circ} \mathrm{C}$. Each value is the mean of three replications averaged over two trials of the experiment. Viability data was transformed with a logistic transformation and regression analysis was run to determine slope and time for viability to decline to $50 \%$ of the original viability at formulation as measured by $\mathrm{CFU} / \mathrm{g}$ of formulation.

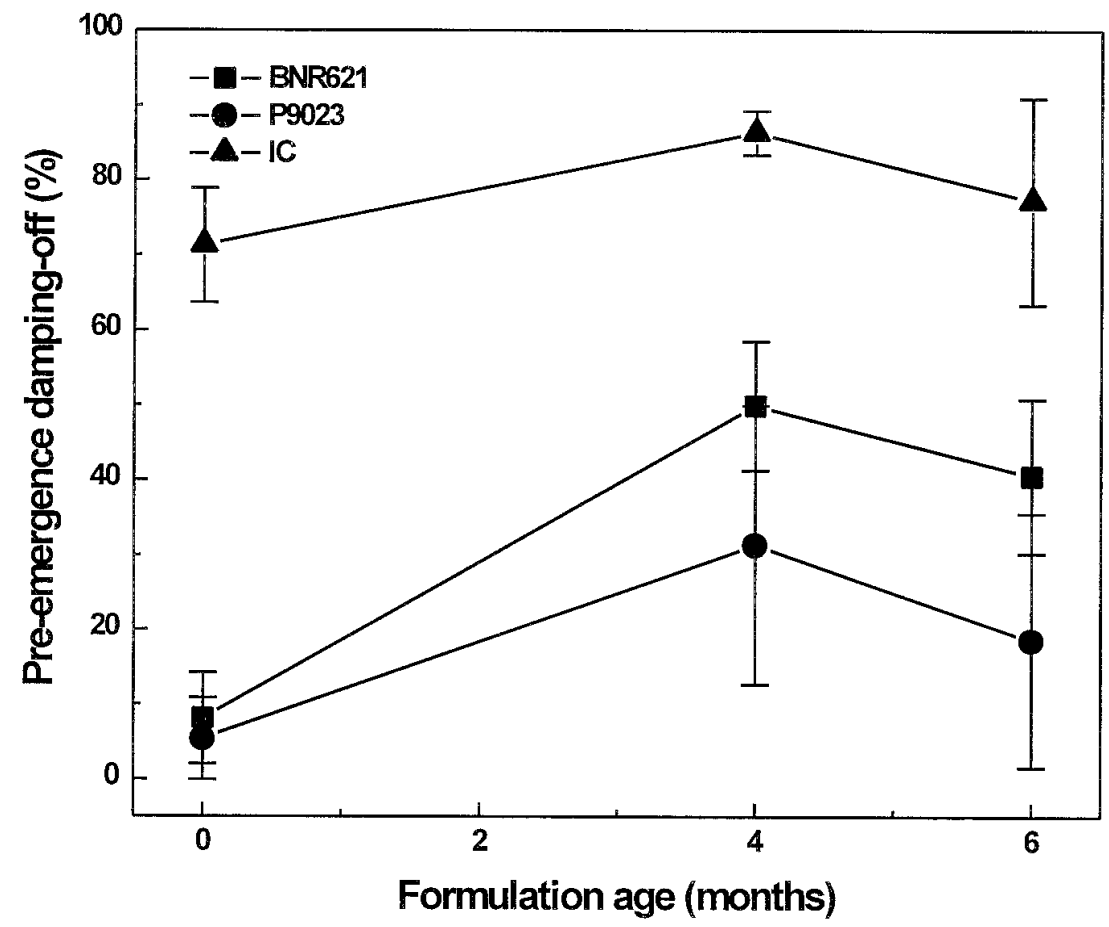

Fig. 4. Effect of formulation age of a Pesta formulation containing isolate BNR621 or P9023 of binucleate Rhizoctonia spp. after storage in closed plastic bags for 0 , 4 , or 6 months at $4^{\circ} \mathrm{C}$ on control of preemergence damping-off of impatiens seed caused by Rhizoctonia solani. Each value is the mean of four replications averaged over two trials of the experiment. 
greater opportunity to colonize the mix and, therefore, suppress P. ultimum. Although a longer period between amendment and seeding may promote better colonization of the mix by the biocontrol agent prior to introduction of the pathogen, periods beyond 1 day may not be practical in the floriculture industry.

An increase in the rate at which potting mix was amended with Pesta or rice flour formulations of BNR fungi did not improve control of preemergence dampingoff of impatiens. Poromarto et al. (28) found that BNR fungi colonize only the epidermal cells of soybean roots, and do not penetrate into cortical tissues. When epidermal cells were colonized by BNR fungi, $R$. solani was unable to colonize nearby cells as induced resistance was established in the host (28). Induced resistance by BNR fungi also has been suggested as a mechanism of control of $R$. solani in other crops $(5,21,32)$. Apparently, additional propagules of BNR fungi associated with the higher rate of amendment did not increase colonization of host tissues or the level of protection against damping-off. Hwang and Benson (21) noted a similar response with BNR fungi in poinsettia, where induced resistance was expressed against $R$. solani but the level of protection was not complete.

Preemergence damping-off of impatiens caused by $R$. solani is a difficult disease to

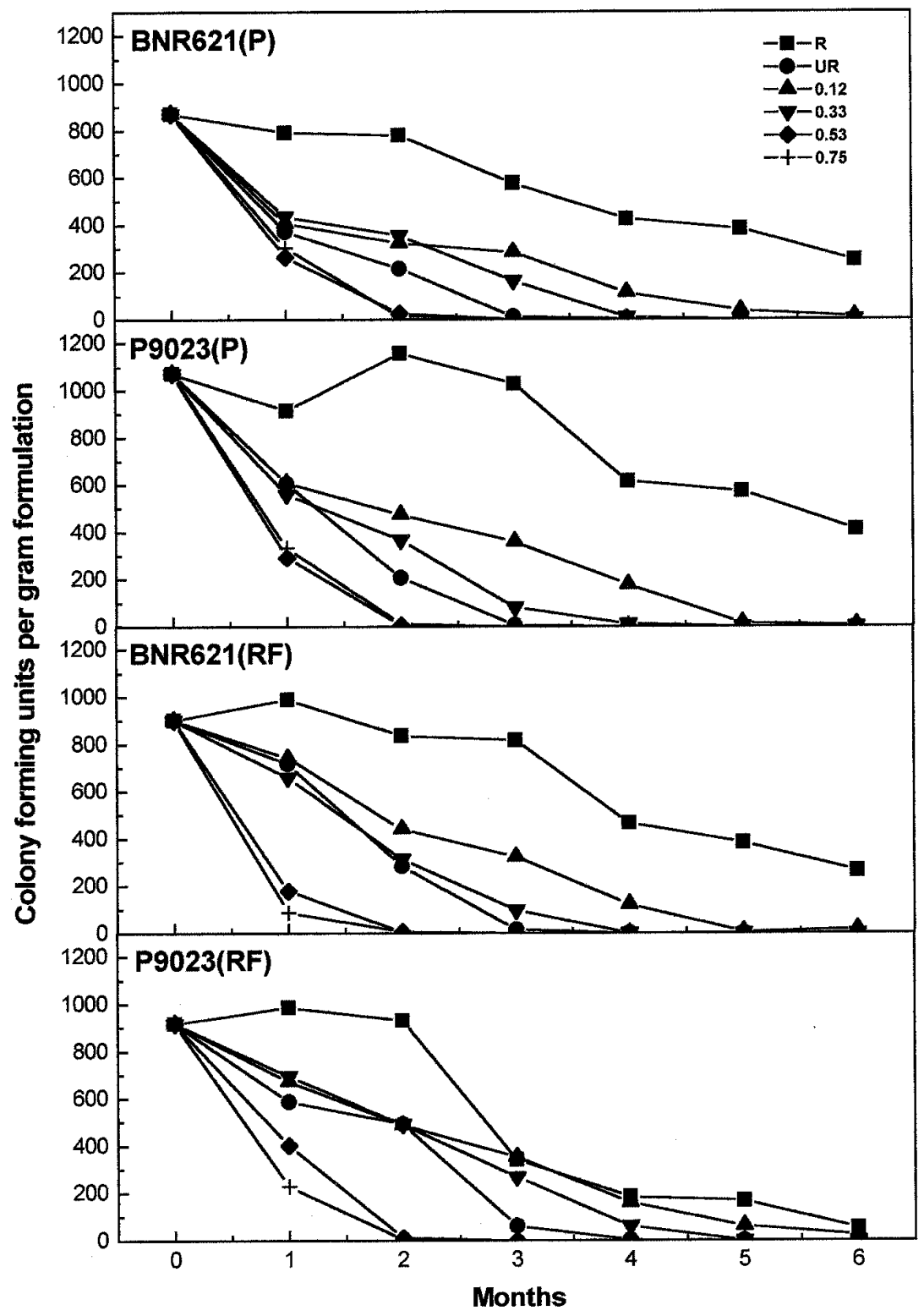

Fig. 5. Effect of constant water activities $\left(\mathrm{a}_{\mathrm{w}}\right)\left(0.12,0.33,0.53\right.$, and $\left.0.75 \mathrm{a}_{\mathrm{w}}\right)$ on the survival (viability) of isolates BNR621 and P9023 of binucleate Rhizoctonia spp. in Pesta (P) and rice flour (RF) formulations at $25^{\circ} \mathrm{C}$. Formulated samples also were exposed to environments where $a_{w}$ was not controlled: about $0.36 \mathrm{a}_{\mathrm{w}}$ at $25^{\circ} \mathrm{C}$ (UR) and about $0.56 \mathrm{a}_{\mathrm{w}}$ at $4^{\circ} \mathrm{C}(\mathrm{R})$. Each value is the mean of three replications averaged over two trials of the experiment. Viability data was transformed with a logistic transformation and regression analysis was run to determine slope and time for viability to decline to $50 \%$ of the original viability at formulation as measured by $\mathrm{CFU} / \mathrm{g}$ of formulation. control even when disease incidence is only 60 to $68 \%$ in the infested control. For instance, with the standard fungicide, thiophanate-methyl, preemergence dampingoff averaged 8 to $10 \%$ over five trials comprising two sets of greenhouse experiments. In three of the five trials, no difference was found in comparison of disease control between the BNR fungi and the fungicide. However, the lack of consistent performance of the BNR fungi with the fungicide across all trials illustrates a serious concern in the adoption of biocontrol tactics for disease control. On the other hand, formulations of the BNR fungi gave significantly better control of damping-off of impatiens than SoilGard, which is based on Trichoderma virens.

Viability of isolates BNR621 and P9023 in Pesta and rice flour formulations stored at $4{ }^{\circ} \mathrm{C}$ declined over a 6-month period regardless of formulation type or isolate. The greatest decrease in viability occurred in the first 2 months. Pesta formulations of mycoherbicidal biocontrol agents Alternaria cassiae and Colletotrichum truncatum (8) and rice flour formulations of Fusarium lateritium and $F$. oxysporum (17) took 12 to 18 months for $50 \%$ reduction of initial propagule concentration. Our studies with BNR fungi in Pesta and rice flour showed that a reduction to $50 \%$ viability of the original formulation $\left(\mathrm{SL}_{50}\right)$ took only 2 months. The fungal stage in which the biocontrol agent exists in formulation could potentially affect survival. Fungi that survive as conidia or chlamydospores in formulation may survive better than fungi such as BNR that survive as hyphal fragments associated with wheat bran in formulation.

Time in storage at $4^{\circ} \mathrm{C}$ of the Pesta formulation of the BNR fungi and biocontrol efficacy was isolate dependent. For isolate BNR621, preemergence damping-off of impatiens was greater with 4- and 6month-old formulation than with fresh formulation. However, with isolate P9023, no difference in age of formulation and biocontrol efficacy was found after up to 6 months in storage. Connick et al. (9) found that an 18-month-old Pesta formulation with less than $50 \%$ of the original concentration of the biocontrol organism still provided good control of targeted weeds. This was not the case with our Pesta formulation of BNR fungi, which was effective up to 6 months after formulation depending on isolate. This period is similar to the shelf life reported on the label of SoilGard with T. virens. However, Lewis and Papavizas (25) found that no correlation existed between CFU of Gliocladium and Trichoderma spp. in soil and extent of survival and saprophytic growth of $R$. solani. Therefore, high titer in formulations may not be critical for some biocontrol agents, particularly BNR fungi, if induced resistance is a mechanism of biocontrol. 
Viability of biocontrol agents in a formulation can be affected by many environmental factors, including $\mathrm{a}_{\mathrm{w}}$ and storage temperature $(8,9)$. In our studies, both $\mathrm{a}_{\mathrm{w}}$ and storage temperature significantly affected the survival of BNR in Pesta and rice flour formulations. Lower $\mathrm{a}_{\mathrm{w}}$ extended the time of survival and maintained the level of viability of the BNR fungi compared with higher $a_{w}$. Our results were similar to those for $C$. truncatum in Pesta formulation, where low $\mathrm{a}_{\mathrm{w}}$ of 0.12 and 0.33 $a_{w}$ extended survival (9). Fungi recognize and respond to $\mathrm{a}_{\mathrm{w}}$ through possible changes in hyphal metabolism. Low $\mathrm{a}_{\mathrm{w}}$ may keep organisms in a low state of physiological activity, extending survival time in the formulation. Thus, if these BNR fungi are commercialized, addition of a desiccant in the packaging or modified atmosphere packaging may be needed to maintain $\mathrm{a}_{\mathrm{w}}$ of the formulation in a favorable range.

Storage temperature also affected the survival of the BNR isolates in Pesta and rice flour formulations. Even with uncontrolled $\mathrm{a}_{\mathrm{w}}$, formulations stored at $4{ }^{\circ} \mathrm{C}$ had an $\mathrm{SL}_{50}$ value near 4.5 months, compared with 1.4 months for formulations stored at $25^{\circ} \mathrm{C}$. Storage of formulations at $4^{\circ} \mathrm{C}$ also extended shelf life for biocontrol agents such as $C$. truncatum, A. cassiae, and $A$. crassa in Pesta (9). However, in studies by Larenas and Montealegre (22), storage pellets at 6 or $22^{\circ} \mathrm{C}$ had no effect on mycelium germination after 5 months. Refrigerated storage of Pesta or rice flour formulations of BNR fungi may be necessary if a commercial product is developed and will no doubt add extra expense to the cost of distributing and storing this product.

Our results demonstrate that BNR fungi in Pesta and rice flour formulations at a $0.47 \%$ rate of amendment to potting mix were comparable to a standard fungicide (thiophanate-methyl) for control of preemergence damping-off of impatiens caused by $R$. solani. Increasing the rate of temperature of $T$. harzianum in alginate

amendment did not improve disease control. No difference in control of preemergence damping-off was found between the closed plastic bag or the misted plug tray method of incubating potting mix amended with formulations of BNR fungi prior to seeding and infesting. Similarly, no difference in control was found between 3- and 1-day incubation times. Viability of BNR fungi in Pesta and rice flour formulations decreased markedly between 0 and 2 months, but both BNR isolates tested survived at least 6 months in formulations stored at $4^{\circ} \mathrm{C}$. When formulation was stored 4 or 6 months at $4^{\circ} \mathrm{C}$, isolate P9023 in the Pesta formulation controlled damping-off to an extent comparable with that of fresh formulation, whereas isolate BNR621 did not. Shelf life of the Pesta formulation of BNR fungi was greatest at low $\mathrm{a}_{\mathrm{w}}$ (i.e., 0.12 and $0.33 \mathrm{a}_{\mathrm{w}}$ ), and storage at $4^{\circ} \mathrm{C}$ improved shelf life compared with storage at $25^{\circ} \mathrm{C}$. Further improvements in maintaining the shelf life of formulated BNR fungi will be needed before these organisms can be developed into a commercial product.

\section{ACKNOWLEDGMENTS}

We thank the USDA CSREES Southern Region IPM Program for providing funds for an assistantship for E. W. Honeycutt; Ball Horticultural Co., West Chicago, IL, for the bedding plant seeds; K. Parker, B. Daughtry, and J. Hwang for technical assistance; and C. Brownie, North Carolina State University, Department of Statistics, for advice on data analysis.

\section{LITERATURE CITED}

1. Anonymous, 2000. Floriculture crops, 1999 summary. Sp Cr 6-1(00). National Agricultural Statistics Service, USDA. Online, publication flor0400.pdf.

2. Benson, D. M., and Baker, R. 1974. Epidemiology of Rhizoctonia solani pre-emergence damping-off of radish: survival. Phytopathology 64:1163-1168.

3. Burns, J. R., and Benson, D. M. 2000. Biocontrol of damping-off of Catharantus roseus caused by Pythium ultimum with Trichoderma virens and binucleate Rhizoctonia fungi. Plant Dis. 84:644-648.

Table 1. Slope and $\mathrm{SL}_{50}$ value for viability of binucleate Rhizoctonia spp. (BNR) in Pesta and rice flour formulations stored in closed containers at constant water activities $\left(\mathrm{a}_{\mathrm{w}}\right)$ at $25^{\circ} \mathrm{C}$ over a 6 -month period

\begin{tabular}{lccc}
\hline $\mathbf{a}_{\mathbf{w}}{ }^{\mathbf{x}}$ & Temperature $\left({ }^{\circ} \mathbf{C}\right)$ & Slope $^{\mathbf{y}}$ & $\mathbf{S L}_{\mathbf{5 0}}$ (months) $^{\mathbf{z}}$ \\
\hline 0.12 & 25 & $-1.15 \mathrm{ab}$ & $2.2 \mathrm{~b}$ \\
0.33 & 25 & $-1.55 \mathrm{bc}$ & $1.8 \mathrm{bc}$ \\
0.53 & 25 & $-3.95 \mathrm{~d}$ & $0.8 \mathrm{~d}$ \\
0.75 & 25 & $-4.00 \mathrm{~d}$ & $0.8 \mathrm{~d}$ \\
Uncontrolled $(\approx 0.36)$ & 25 & $-2.03 \mathrm{c}$ & $1.4 \mathrm{c}$ \\
Uncontrolled $(\approx 0.56)$ & 4 & $-0.79 \mathrm{a}$ & $4.5 \mathrm{a}$ \\
\hline
\end{tabular}

${ }^{\mathrm{x}}$ Formulations in closed containers were exposed to constant $\mathrm{a}_{\mathrm{w}}\left(0.12,0.33,0.53\right.$, and $\left.0.75 \mathrm{a}_{\mathrm{w}}\right)$ over a 6-month period at $25^{\circ} \mathrm{C}$. Samples of formulations also were stored in closed containers under uncontrolled environments at $25^{\circ} \mathrm{C}$ and approximately $0.36 \mathrm{a}_{\mathrm{w}}$ and at $4{ }^{\circ} \mathrm{C}$ and approximately 0.56 $\mathrm{a}_{\mathrm{w}}$.

${ }^{y}$ Slope and $\mathrm{SL}_{50}$ value for viability data combined over BNR isolate and formulation for two trials of the experiment. The slope represents the rate of decline of CFU of BNR fungi per gram of formulation over time. A logistic transformation was used to transform viability data prior to regression analysis.

${ }^{\mathrm{z}} \mathrm{SL}_{50}=$ time for viability to decline to $50 \%$ of the original viability at formulation as measured by $\mathrm{CFU} / \mathrm{g}$ of formulation. Values within a column followed by a different letter are significantly different $(P \leq 0.05)$ according to the least significant difference procedure.
4. Cardoso, J. E., and Echandi, E. 1987. Biological control of Rhizoctonia root rot of snap bean with binucleate Rhizoctonia-like fungi. Plant Dis. 71:167-170.

5. Cardoso, J. E., and Echandi, E. 1987. Nature of protection of bean seedlings from Rhizoctonia root rot by a binucleate Rhizoctonia-like fungus. Phytopathology 77:1548-1551.

6. Cartwright, D. K., and Benson, D. M. 1996. Efficacy of binucleate Rhizoctonia fungi to control Rhizoctonia damping-off in Impatiens. (Abstr.) Phytopathology 86:S104-105.

7. Cline, M. N., Chastagner, G. A., Aragaki, M., Baker, R., Daughtrey, M. L., Lawson, R. H., MacDonald, J. D., Tammen, J. F., and Worf, G. 1988. Current and future research direction of ornamental pathology. Plant Dis. 72:926934.

8. Connick, W. J., Boyette, C. D., and McAlpine, J. R. 1991. Formulation of mycoherbicides using a pasta-like process. Biol. Control 1:281-287.

9. Connick, W. J., Daigle, D. J., Boyette, C. D., and Williams, K. S. 1996. Water activity and other factors that affect the viability of Colletotrichum truncatum conidia in wheat flourkaolin granules ('Pesta'). Biocontrol Sci. Technol. 6:277-284.

10. Cubeta, M. A., and Echandi, E. 1991. Biological control of Rhizoctonia and Pythium damping-off of cucumber: An integrated approach. Biol. Control 1:227-236.

11. Elad, Y., Hadar, Y., Hadar, E., and Chet, I. 1981. Biological control of Rhizoctonia solani by Trichoderma harzianum in carnation. Plant Dis. 65:675-677.

12. Escandi, A. R., and Echandi, E. 1991. Protection of potato from Rhizoctonia canker with binucleate Rhizoctonia fungi. Plant Pathol. 40:197-202.

13. Fravel, D. R., Marois, J. J., Lumsden, R. D. and Connick, W. J., Jr. 1985. Encapsulation of potential biocontrol agents in an alginate-clay matrix. Phytopathology 75:774-777.

14. Gutierrez, W. A., Shew, H. D., and Melton, T. A. 1997. Sources of inoculum and management of Rhizoctonia solani damping-off on tobacco transplants under greenhouse conditions. Plant Dis. 81:604-606.

15. Harman, G. E. 2000. Myths and dogmas of biocontrol: Changes in perceptions derived from research on Trichoderma harzianum T22. Plant Dis. 84:377-393.

16. Harris, A. R., Schisler, D. A., Neate, S. M., and Ryder, M. H. 1994. Suppression of damping-off caused by Rhizoctonia solani and growth promotion, in bedding plants by binucleate Rhizoctonia spp. Soil Biol. Biochem. 26:263-268.

17. Hebbar, K. P., Lumsden, R. D., Lewis, J. A., and Poch, S. M. 1998. Formulation of mycoherbicidal strains of Fusarium oxysporum. Weed Sci. 46:501-507.

18. Honeycutt, E. W., and Benson, D. M. 2000. Efficacy of binucleate Rhizoctonia spp. for control of pre-emergence damping-off of bedding plants caused by Rhizoctonia solani. (Abstr.) Phytopathology 90:S126.

19. Honeycutt, E. W., and Benson, D. M. 2000. Effects of formulation age and rate of binucleate Rhizoctonia spp. on control of pre-emergence damping-off of impatiens caused by Rhizoctonia solani. (Abstr.) Phytopathology 90:S36.

20. Howell, C. R. 1981. Effect of Gliocladium virens on Pythium ultimum, Rhizoctonia solani, and damping-off of cotton seedlings. Phytopathology 72:496-498.

21. Hwang, J., and Benson, D. M. 2001. Resistance of poinsettia cultivars against Rhizoctonia stem rot induced by binucleate Rhizoctonia. (Abstr.) Phytopathology 91:S41.

22. Larenas, C., and Montealegre, J. R. 1996 
Effect of the storage temperature and nutrient amount on the viability of Trichoderma harzianum pellets. Fitopatologia 31:66-69.

23. Lewis, J. A., Fravel, D. R., Lumsden, R. D., and Shasha, B. 1995. Application of biocontrol fungi in granular formulations of pregelatinized starch-flour to control damping-off diseases caused by Rhizoctonia solani. Biol. Control 5:397-404.

24. Lewis, J. A., Fravel, D. R., and Papvizas, G. C. 1995. Cladorrhinum foecundissimum: a potential biological control agent for the reduction of Rhizoctonia solani. Soil Biol. Biochem. 27:863-869.

25. Lewis, J. A., and Papavizas, G. C. 1985. Effect of mycelial preparations of Trichoderma and Gliocladium on populations of Rhizoctonia solani and the incidence of damping-off. Phytopathology 75:812-817.

26. Lumsden, R. D., Lewis, J. A., and Fravel, D. R. 1995. Formulation and delivery of biocontrol agents for use against soilborne plant pathogens. Pages 166-182 in: Biorational Pest Control Agents, Formulation and Delivery. F.

R. Hall and J. W. Barry, eds. Am. Chem. Soc. Washington, DC.

27. Lumsden, R. D., and Locke, J. 1989. Biological control of damping-off caused by Pythium ultimum and Rhizoctonia solani with Gliocladium virens in soilless mix. Phytopathology 79:361-366.

28. Poromarto, S. P., Nelson, B. D., and Freeman, T. P. 1998. Association of binucleate Rhizoctonia with soybean and mechanism of biocontrol of Rhizoctonia solani. Phytopathology 88:1056-1067.
29. Ross, R. E., Keinath, A. P., and Cubeta, M. A 1998. Biological control of wirestem on cabbage using binucleate Rhizoctonia spp. Crop Prot. 17:99-104.

30. Villajuan-Abgona, R., Kageyama, K., and Hyakumachi, M. 1996. Biocontrol of Rhizoctonia damping-off of cucumber by nonpathogenic binucleate Rhizoctonia. Eur. J Plant Pathol. 102:227-235.

31. Winston, P. W., and Bates, D. H. 1960. Saturated solutions for the control of humidity in biological research. Ecology 41:232-237.

32. Xue, L., Charest, P. M., and Jabaji-Hare, S. H. 1998. Systemic induction of peroxidases, 1,3_beta-glucanases, chitinases, and resistance in bean plants by binucleate Rhizoctonia species. Phytopathology 88: 359-365. 